\title{
BMJ Open Quality Implementation of a weekend ceilings of care intervention in surgical inpatients at a District General Hospital
}

\author{
Simon Morris, ${ }^{1}$ Andrine Van Woerden, ${ }^{2}$ Stephen Shering ${ }^{2}$
}

To cite: Morris S, Van Woerden A, Shering S Implementation of a weekend ceilings of care intervention in surgical inpatients at a District General Hospital. BMJ Open Quality 2019;8:e000779. doi:10.1136/ bmjoq-2019-000779

Received 26 July 2019 Revised 19 November 2019 Accepted 23 November 2019
Check for updates

(c) Author(s) (or their employer(s)) 2019. Re-use permitted under CC BY-NC. No commercial re-use. See rights and permissions. Published by BMJ.

${ }^{1}$ Department of General Surgery, Abertawe Bro Morgannwg University Health Board, Port Talbot, UK

${ }^{2}$ Department of General Surgery, Princess of Wales Hospital, Bridgend, UK

Correspondence to Dr Simon Morris; s.morris@doctors.org.uk

\section{PROBLEM}

At this district general hospital, out-ofhours rapid response calls are attended by members of both the on-call surgical and medical team. Thus, it is not uncommon that no-one on this rapid response team has previously met the unwell patient. This was placing unnecessary anxiety on junior doctors during on-call shifts, who may be required to make escalation decisions for patients without adequate understanding of the patient's clinical background and prior ceilings of care discussions.

\section{BACKGROUND}

Weekends feature a break in continuity of patient care; from consultant-led to an on-call team. This may result in patients being subjected to distressing investigation and management by on-call doctors who make escalation decisions without a detailed understanding of the patient's circumstances and prior discussions regarding their ceiling of care. Thus, continuity in patient care relies on good documentation and decision-making by the patient's regular team prior to the weekend and other out-ofhours periods. In addition, it is essential that these decisions are easily interpretable by the on-call team who may be making urgent decisions regarding an acutely deteriorating patient.

Defining escalation status for a patient involves discussion with patients and families, with a good understanding of their medical history. This directly results in what may be considered a 'ceiling of care'; which may range from intensive care unit to ward-based care and do not attempt cardiopulmonary resuscitation orders. Evidence shows that good documentation of escalation status ensures that patients receive optimal care out-of-hours as well as reducing stress among on-call doctors. ${ }^{12}$

\section{MEASUREMENT}

During a 1 month period, records for surgical inpatients on a single general surgical ward were reviewed for four consecutive weekends. On a Friday afternoon, data were collected on presence of weekend treatment plan, resuscitation decision and level of escalation documented in the notes. Following the weekend, records were analysed to establish if any clinical reviews were requested by nursing staff during these out-of-hours periods or if any rapid response calls had been made (cycle $1)$. This was confirmed by clarifying requests for patient reviews on the 'Hospital at Night' database, patient notes for evidence of a clinical review and with hospital switchboard about any rapid response calls placed on the ward.

\section{DESIGN}

In the initial data collection phase documentation of escalation status was found to be lacking. An intervention sticker was designed for inclusion in the notes to prompt the surgical team to provide a summary of patient's ongoing management plan and escalation status (figure 1). This did not replace any statutory documentation that was required to record DNACPR status. Specifically, the legally required 'Red Form' still needed to be completed by the relevant team and placed at the front of the notes for the DNACPR decision to be valid.

All members of the surgical team and nursing staff were briefed on the sticker and its' implications. Junior doctors were asked to implement the intervention during the consultant-led ward round. This intervention was prompted to be completed on a Friday morning consultant ward round, prior to the weekend at first. The authors believed that this would be a pertinent time to prepare patients for the out-of-hours, on-call team care provided at weekends. However, it was hoped that the sticker would soon be adopted 


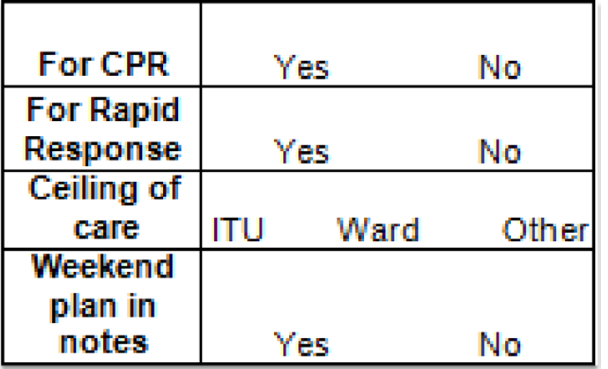

Figure 1 Copy of Intervention Sticker Used.

for any new patients likely to have an inpatient stay, so that the relevant information was also recorded in order to aid out-of-hours night staff.

In cycle 2, patient's notes were rereviewed to collect identical data before and after four consecutive weekends. This data collection cycle looked at compliance with the sticker and subsequent documentation of the aforementioned domains.

\section{RESULTS}

Sixty-six patients were included in cycle 1 . At baseline, the number of patients with a written weekend plan for the weekend was $38 \%(n=25)$. Three per cent $(n=2)$ had escalation status documented in the notes and $1.5 \%(\mathrm{n}=1)$ patient had resuscitation status documented (figure 2). During this period, 0 patients had a defined ward-based ceiling of care and 1 patient was DNACPR. Nursing staff requested 19 clinical reviews and 2 rapid response calls according to patient notes, hospital at night database and switchboard records.

Cycle 2 included 58 patients. Overall, the intervention sticker improved documentation in the notes. The number of patients with a written weekend plan for the weekend was $85 \%(n=49)$, escalation status $79 \% \quad(n=46)$ and resuscitation status $81 \%(\mathrm{n}=47)$. During cycle 2, 4 patients had a defined ward-based ceiling of care and 10 patients had a DNACPR order. Nursing staff requested

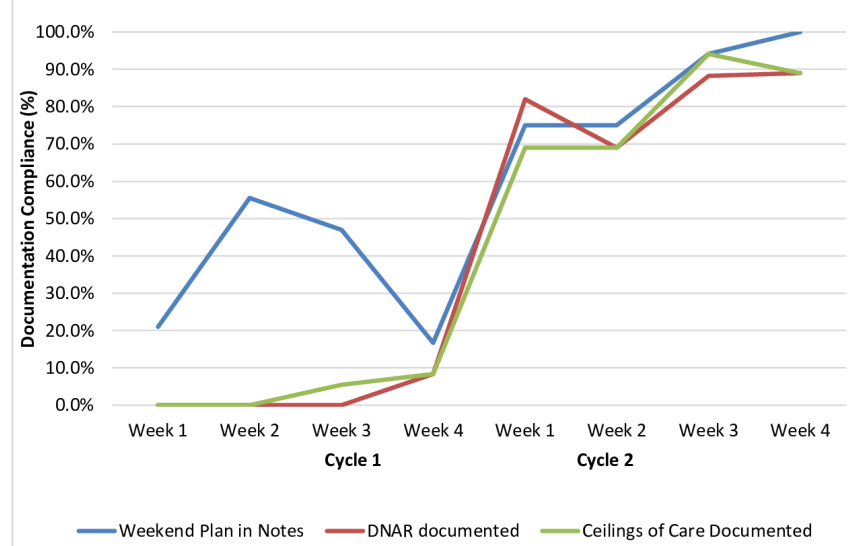

Figure 2 Run Chart Demonstrating Compliance with Weekend Plan, DNACPR order and Ceilings of Care Documentation in Cycle 1 and Cycle 2. three clinical reviews during weekends in this period and one rapid response call.

Notably in the fourth weekend of cycle 2, $100 \%$ of patients had a weekend plan and $89 \%$ had both resuscitation and escalation status documented.

The intervention sticker provided a succinct and useful adjunct to patient notes which prompted surgical teams to consider the documentation of weekend plan and escalation status. This reflects evidence from other authors who state that escalation decisions are best planned by a patient's daily consultant-led team. ${ }^{3-5}$ The majority of out-of-hours clinical deterioration may be potentially avoidable with adequate anticipation and planning. ${ }^{6}$ The General Medical Council (GMC) guidelines state that inpatients at risk of deterioration should have their escalation and resuscitation status reviewed on a regular basis. $^{7}$

Junior doctors from medical and surgical teams alike found the sticker a valuable and user-friendly adjunct; however, this was on an anecdotal basis and not formally measured. Nursing staff found it a useful reference to clarify a patient's plan, when they would have otherwise queried this with the on-call team. This is reflected in the number of clinical reviews requested by nursing staff between cycle $1(n=19)$ and cycle $2(n=3)$; which has obvious benefits to the on-call doctor's workload and time management.

On initial implementation of the sticker, a Friday morning ward round was considered the best time to act as a prompt and ensure that documentation was updated for the upcoming weekend. However, the authors hope that this has added benefits for evenings, weekday out-ofhours and night staff alike. The sticker was designed to be valid until crossed off or superseded, so it would apply to all out-of-hours work following insertion into the notes unless cancelled. Likewise, the authors hope that the sticker serves as a general prompt to consider patients' escalation status at all times, including at the point of admission.

The data collection relies on the accuracy of patient notes, hospital at night database and switchboard records for the measurement of patient reviews and rapid response calls.

The authors recognise that the sticker may not represent an original intervention to many and the improvement may only be transient as a result of the novelty in this hospital. In addition, the sticker runs over a short timescale which has obvious limitations towards the intervention's longevity. When presenting the results locally, it was proposed that subsequent foundation doctors would maintain the intervention and reaudit periodically to determine the long-term implications of the sticker; however, further reaudit has not been presented in this paper. Ultimately, whether or not the intervention is maintained, the authors hope that it has prompted all healthcare professionals to consider the importance of ceilings of care, respecting patient's decisions towards escalation and documenting these appropriately for out-of-hours colleagues. 


\section{CONCLUSIONS}

Following intervention, the documentation of patient treatment plans and escalation status improved, which coincided with a fall in the number of clinical reviews requested by nursing staff. Introduction of the intervention sticker prompted surgical teams to consider appropriate ceilings of care in the event of deterioration and provide nursing staff with an appropriate treatment plan. This reiterates the value of a simple intervention that which can have positive impact on patient care.

Acknowledgements Nursing staff and general surgical teams at Princess of Wales Hospital.

Contributors SM led data collection and is lead author. AVW assisted in data collection and coauthored the paper. SS was supervising consultant and coauthor.

Funding The authors have not declared a specific grant for this research from any funding agency in the public, commercial or not-for-profit sectors.

Competing interests None declared.

Patient consent for publication Not required.

Provenance and peer review Not commissioned; externally peer reviewed.

Data availability statement Data are available upon request.

Open access This is an open access article distributed in accordance with the Creative Commons Attribution Non Commercial (CC BY-NC 4.0) license, which permits others to distribute, remix, adapt, build upon this work non-commercially, and license their derivative works on different terms, provided the original work is properly cited, appropriate credit is given, any changes made indicated, and the use is non-commercial. See: http://creativecommons.org/licenses/by-nc/4.0/.

\section{REFERENCES}

1 Dahill M, Powter L, Garland L, et al. Improving documentation of treatment escalation decisions in acute care. BMJ Qual Improv Report 2013;2:u200617.w1077.

2 Grainge C, Traer E, Fulton J. Do weekend plan standard forms improve communication and influence quality of patient care? Postgrad Med J 2005;81:524-5.

3 Stockdale C, Trivedi B, Jerome E, et al. Implementation of a combined cardiopulmonary resuscitation and treatment escalation plan document in a district general Hospital. BMJ Qual Improv Rep 2013;2:u202653.w1236.

4 Slack P, Rose A. Ceiling of care decisions at an older person's mental health unit in Gloucestershire. BMJ Qual Improv Rep 2015;4:u207618. w3050.

5 Fadel MG, Parekh K, Hayden P, et al. Improving resuscitation decisions: a trust-wide initiative. BMJ Open Quality2018;7:e000268.

6 Hodgetts TJ, Kenward G, Vlackonikolis I, et al. Incidence, location and reasons for avoidable in-hospital cardiac arrest in a district general hospital. Resuscitation 2002;54:115-23.

7 General Medical Council (GMC). Treatment and care towards the end of life: good practice in decision making, 2010. Available: https://www. gmc-uk.org/ethical-guidance/ethical-guidance-for-doctors/treatmentand-care-towards-the-end-of-life [Accessed 8 Apr 2019]. 